\title{
Diagnostics and monitoring of microprocessor-controlled excitation power supply unit for synchronous motors
}

\begin{abstract}
This article presents a excitation power supply unit for synchronous motors with a microprocessor control system. The theoretical basics of reactive power regulation with a synchronous motor and influence of load on the permissible operating range are discussed. The possibilities of controlling the motor by a microprocessor system in the developed device during asynchronous start-up and synchronous operation are presented. The ability to monitor and record the status of the drive, which allows us to analyze the sequence of events in case of emergencies, is also presented. Dedicated software for diagnostic and service operation is demonstrated. The selected diagnostic functionality is also discussed.
\end{abstract}

Key words: synchronous motor, excitation current control, reactive power controller, microprocessor control, remote control, monitoring

\section{INTRODUCTION}

Large-power synchronous motors are used in industry to drive machines that do not require speed control. Typical applications are the main fan drives for ventilating the underground part of mines, compressors, and the converter drives of Ward Leonard motor control systems (which can still be found in some industrial applications).

One of the basic operational issues is the start-up process of the motor. For salient-pole synchronous motors, the direct asynchronous start-up or reactor start-up procedure is customarily realized. The startup procedure requires the proper sequence of actions according to the current state of the drive $[3,5,9,13$, 21, 22]. An unsuccessful start-up can lead to fixing a motor work at sub-synchronous speed, long-term operation with current greater than the rated value, electromagnetic torque pulsation, and speed oscillation resulting in significant mechanical overload on the motor shaft and early wear of the bearings. After an unsuccessful start-up, another attempt to start the motor is possible after the motor shaft has stopped. Drives with a high factor of inertia could have time to wind down for up to several dozens of minutes. The inrush currents repeatedly exceed the rated values, resulting in the significant heating of the motor winding.
For this reason, the number of start-up attempts within a specified time period should be limited.

Under-loaded synchronous motors are often used as adjustable reactive power compensators for the fundamental harmonic - locally and in systems with superior reactive power controllers $[4,6,11,12]$. Reactive power regulation is achieved by changing the current in the field winding during synchronous operation $[1,8]$. Synchronous operation is possible only within a limited range of the load angle. After exceeding the permissible load angle, the motor falls out of synchronism $[2,12,18]$ and should be placed in emergency shutdown.

Active power $P$ taken by the motor during synchronous operation is described by the following equation $[2,18]$ :

$$
P=m\left(\frac{U_{f} E_{w}}{X_{d}} \sin \vartheta+\frac{1}{2} U_{f}^{2}\left(\frac{1}{X_{q}}-\frac{1}{X_{d}}\right) \sin (2 \vartheta)\right)(1)
$$

where:

$m$ - number of phases,

$U_{f}$ - phase-to-phase voltage;

$X_{d}-d$-axis reactance,

$X_{q}-q$-axis reactance,

$\vartheta$ - load angle,

$E_{w}$ - electromotive force induced in the winding of the stator. 
Assuming the linearity of the magnetization characteristics, the electromotive force induced in the field winding is dependent on the excitation current and expressed by the following equation:

$$
E_{w}=\frac{I_{w}}{k_{w}}
$$

where:

$I_{w}-$ excitation current,

$k_{w}-$ constant value connected with the motor structure.

From Equations (1) and (2), it follows that the load angle of the motor is influenced by the value of active power (proportional to the load torque), value of the supply voltage, and value of the excitation current.

The currents in the $d$ and $q$ axes depend on load angle $\vartheta$ and electromotive force $E_{w}$, which is related to the field current according to the following equations:

$$
\begin{gathered}
I_{d}=\frac{E_{w}-U_{f} \cos \vartheta}{X_{d}} \\
I_{q}=\frac{U_{f} \sin \vartheta}{X_{q}}
\end{gathered}
$$

Stator current $I$ of the machine can be determined from dependence

$$
I=\sqrt{I_{d}^{2}+I_{q}^{2}}
$$

where active current $I_{P}$ has value

$$
I_{P}=\frac{P}{3 U_{f}}
$$

Reactive power $Q$ of the motor can be written as

$$
Q= \begin{cases}-3 U_{f} \sqrt{I^{2}-I_{P}^{2}} & \text { dla } \vartheta<\vartheta_{0}, \\ 3 U_{f} \sqrt{I^{2}-I_{P}^{2}} & \text { dla } \vartheta \geq \vartheta_{0},\end{cases}
$$

where $\vartheta_{0}$ - load angle while working with $\cos \varphi=1$, assuming that the positive value of the reactive power means consumption of inductive power by the motor and the negative value means the return of inductive power to the grid (consumption of the capacitive reactive power).
Figure 1 shows the typical characteristics of reactive power depending on the field current with the limitation due to the rated field current value.

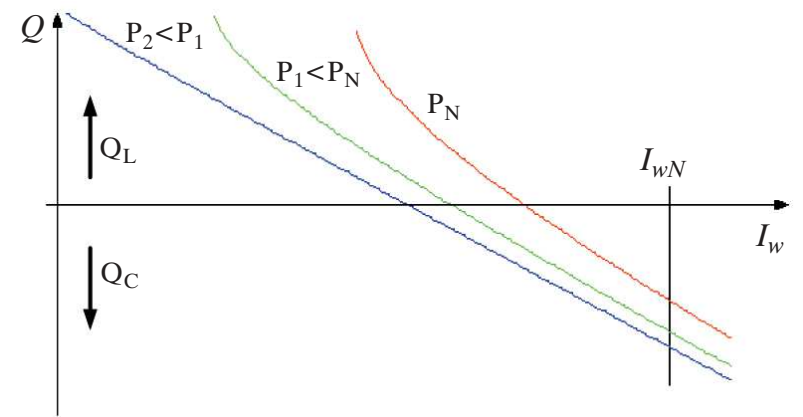

Fig. 1. Dependence of reactive power on field current for different values of active power

The follow-up reactive power compensation realized by the synchronous motor can lead to changes in the load angle at an unchanged load torque. Figure 2 shows the typical characteristic of the load angle depending on the field current value.

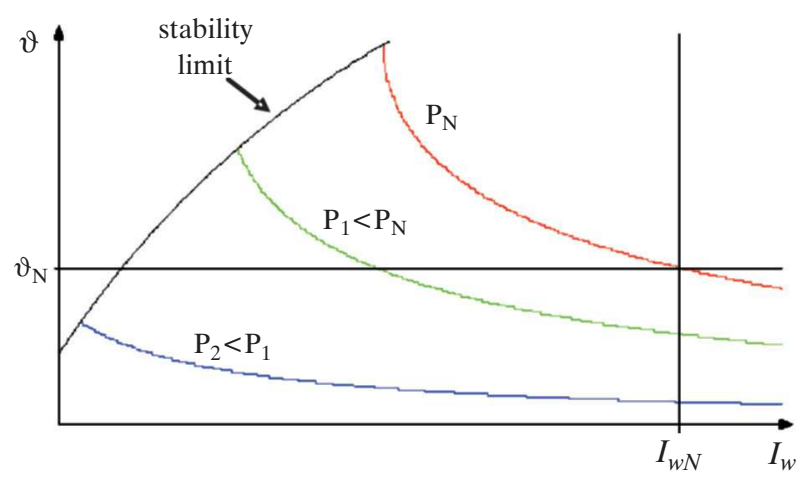

Fig. 2. Dependency of load angle on field current for different values of active power

As can be seen in Figure 2, it is possible to operate an under-loaded synchronous motor with a load angle greater than the nominal. However, exceeding the limit of static stability leads to its falling out of synchronous state and the switching off the drive by the protection units.

One of the most-commonly used characteristics describing the operation state of the synchronous motor are Mordey's curves (also called V-curves due to their form). These curves can be determined analytically upon the parameters available on the motor rated data plate and the values of the $X_{d}$ and $X_{q}$ synchronous reactances. Taking the correct values of $X_{d}$ and $X_{q}$ reactance to the calculation is necessary to properly determine the range of the field current according to the motor active power load, to provide stable operation in the synchronous state. 
Figure 3 shows the typical forms of Mordey's curves with marks signifying the allowable range of operation in the synchronous motor.

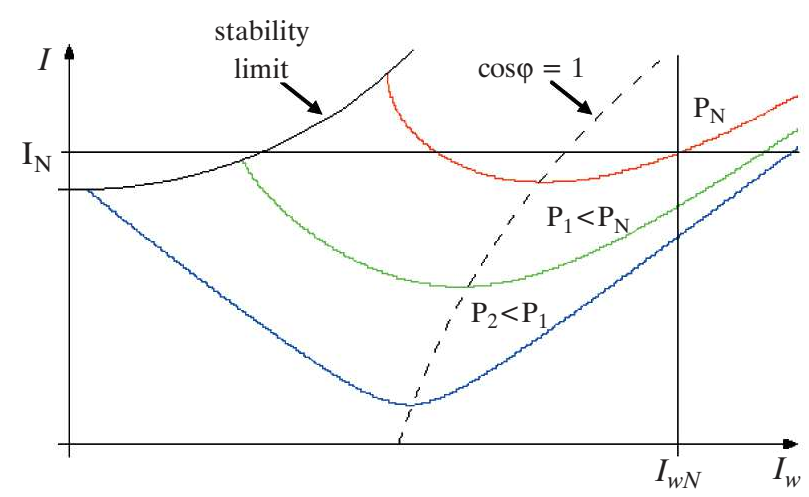

Fig. 3. Mordey's curves with allowable range of motor operation

In order to ensure stable operation in the synchronous state, the field current must be appropriately controlled, taking into account the influence of the load torque, supply voltage value, reactive power set value, and the stator and field current rated values, all the while maintaining the load angle into the allowable range $[1,2,12,15,18]$.

\section{MICROPROCESSOR-CONTROLLED UNIT FOR SYNCHRONOUS MOTOR EXCITATION SUPPLY}

Figure 4 shows a block diagram of the microprocessor-controlled excitation power supply unit designed to cooperate with $6 \mathrm{kV}$ large-power synchronous motors with rated field currents up to $400 \mathrm{~A}[5,8]$.

The device includes a thyristor rectifier and transistor switches to turn the start-up resistor on and off, supervised by the microprocessor system.
The transistor switches allow for the flow of the bi-directional current induced in the excitation winding during motor start-up. A non-contact excitation circuit improves the reliability and durability of the system.

The software implemented in the microprocessor system allows for autonomous control of motor operation, including:

- start-up [8-10, 21, 22] (also for inrush choke),

- control of the circuit breakers in the $6 \mathrm{kV}$ switching station supplying the motor,

- control of the thyristor rectifier in the excitation circuit,

- control synchronous state operation of the motor with the possibility of maintaining the set value of the field current or reactive power,

- control the field current forcing process,

- technology or emergency switch-off procedure with discharge of the excitation winding energy [10].

In addition, the device can be integrated with a superordinated reactive power compensation system, realizing step-less follow-up reactive power compensation during the synchronous state of motor operation [6].

Using the device to control the main fan drive of the underground ventilation system of mine introduces strict criteria for drive operation. Mining regulations require that, in addition to a working fan in each up-cast shaft, an auxiliary fan that can start working within ten minutes is required [19]. Failure of the main fan and a failed start-up of the auxiliary fan lead to a serious threat to the health and life of the underground crew. An interruption of at least 20 minutes results in stopping work and leading the personnel towards intake ventilation shafts or to ground level [19].

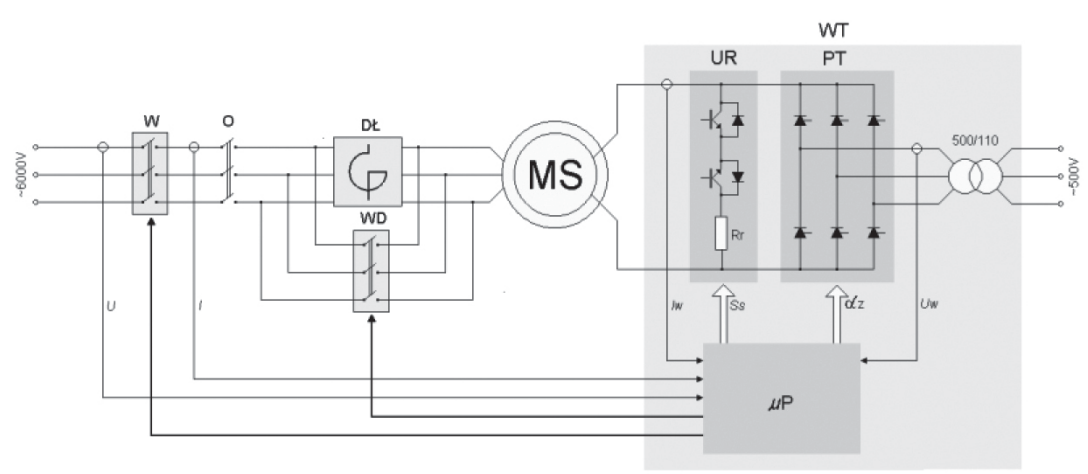

Fig. 4. Diagram of the motor control system: MS - synchronous motor; WT - thyristor exciter; $\mu P$ - microprocessor system; PT - thyristor rectifier; UR - start-up system; $W$ - circuit breaker; $O$ - disconnector; WD - choke circuit breaker; DE - inrush choke 
Therefore, it is important to determine the proper start-up parameters and limit the range of field current control during synchronous operation of the motor. The monitoring and diagnostics of the operation of the drive (both on-line and with the ability to browse archived data) are useful in case of possible malfunctions.

\section{DATA RECORDING AND MONITORING OPERATING STATUS OF THE DEVICE}

The microprocessor system of the device records the measurement data of active and reactive power, stator supply voltage, stator current, and field current. Apart from that, it records all status or operating modes changes, changes of switches states in the $6 \mathrm{kV}$ power supply switching station, the realization of additional procedures (e.g., field current forcing in case of supply voltage dips [7, 13]), the occurrence of alarm or emergency events detected by the software algorithms of the microprocessor system or by external protection devices. Recorded information is stored in non-volatile memory and can be used to analyze of the drive operation and possibly diagnose malfunctions. It is also possible to transfer the recorded information to the external device in real time via the available communication interfaces.

One of the elements of the device's HMI is the LCD display, which allows for monitoring the status of operation of the drive. Current status information, alarm and emergency alerts, and waveforms of the recorded measured values are displayed. Figure 5 shows selected information displayed on the LCD of the device.

The microprocessor-controlled excitation power supply unit is equipped with a set of communication interfaces that cooperate with diagnostic-service software or external supervisor systems. Also available are MODBUS ASCII, and RTU interfaces [17] of RS-485 standard, USB interface [16], and an ethernet interface for TCP/IP communications [20] with user authentication and an IP address filtering system to establish a connection. The ethernet TCP/IP connection is available in client mode or server mode. In addition, an HTTP server [14] has been implemented in the device software for accessing basic information using a web browser with JavaScript support.

Figure 6 shows sample pages created by the HTTP server built into the microprocessor software. The content of the pages is automatically refreshed on a web browser every ten seconds.

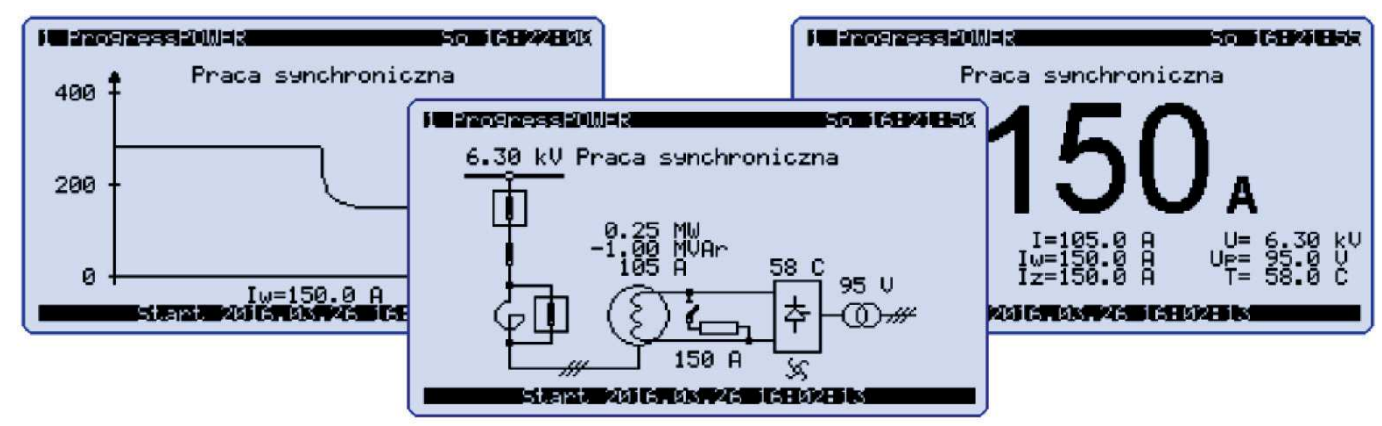

Fig. 5. Monitoring of drive operation on the LCD of the device

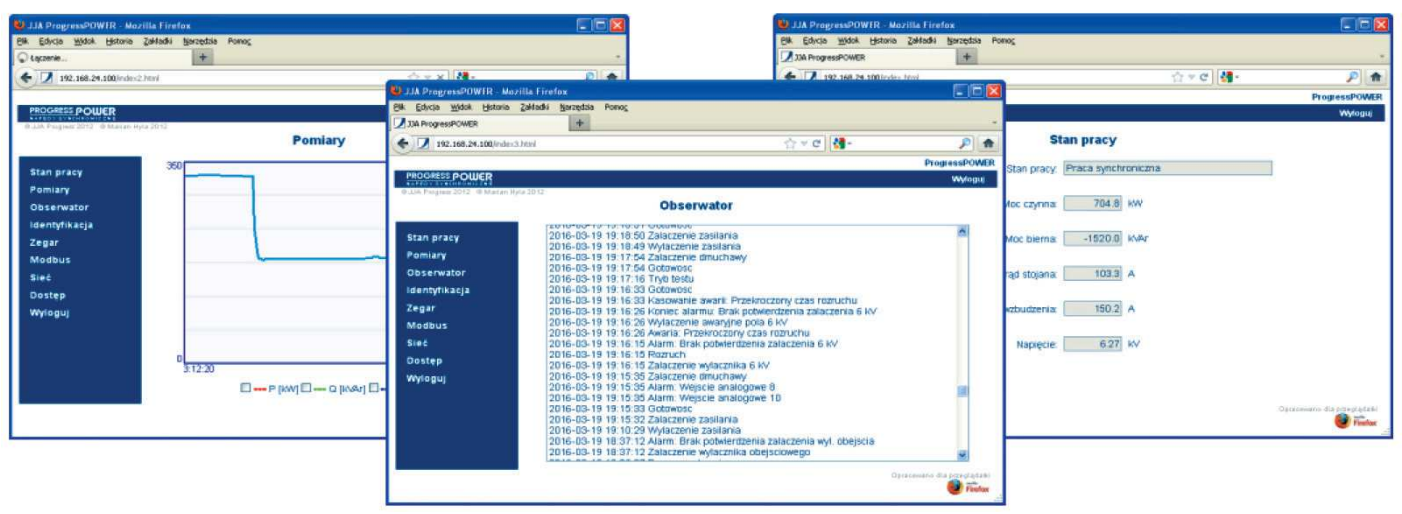

Fig. 6. Monitoring of drive operation using web browser 


\section{DIAGNOSTIC SOFTWARE}

For a detailed analysis of the operation of the drive with the microprocessor-controller excitation unit, diagnostic and service software has been developed for the Windows system. The software enables the monitoring and controlling of the device via RS-485, USB, or ethernet TCP/IP interfaces.

Figure 7 shows the appearance of the software interface dedicated to diagnostics and servicing.

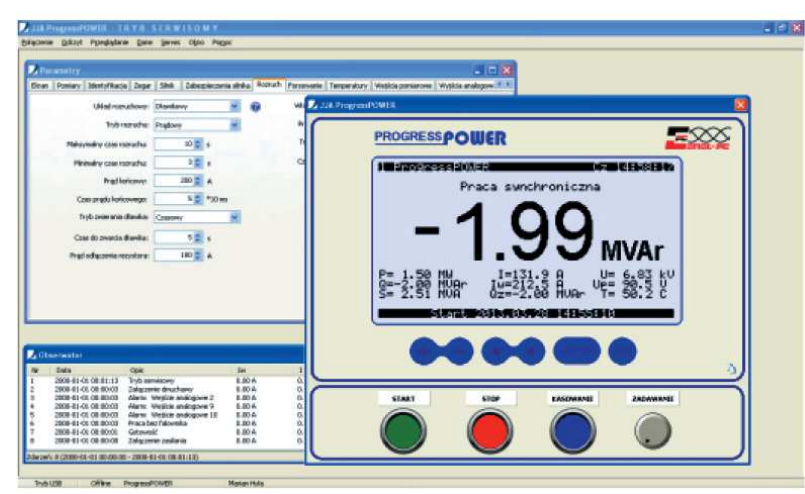

Fig. 7. Diagnostic and service software

One of the diagnostic functions is the ability to capture the events related to the drive operation, recorded into the non-volatile memory of the microprocessor system. Recording of this type of information into the device and the ability to browse it at any time are useful for analyzing the behavior of the drive in the event of unusual or unforeseen events related to the operation of the drive or the power supply system.

Figure 8 shows an example sequence of events read from the microprocessor system. Diagnostic software allows to view, search, sort, and filter the read information.

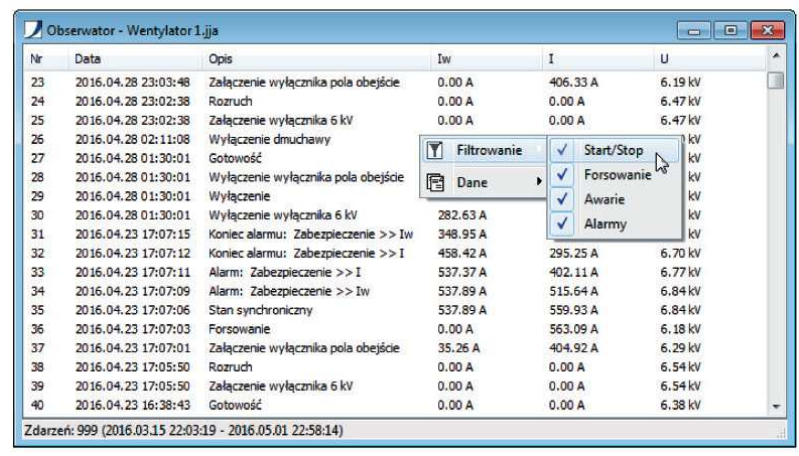

Fig. 8. Analysis of events recorded by microprocessor system

Diagnostic software enables the reading of the recorded waveforms and synchronization of measurements with the recorded event in a common window. Figure 9 shows the window for analyzing the drive operating condition. A typical waveform of the excitation current in the initial phase of motor start-up is caused by the use of a unidirectional LEM-type current converter and caused by the signal sampling period for the measurement procedure of the microprocessor system.

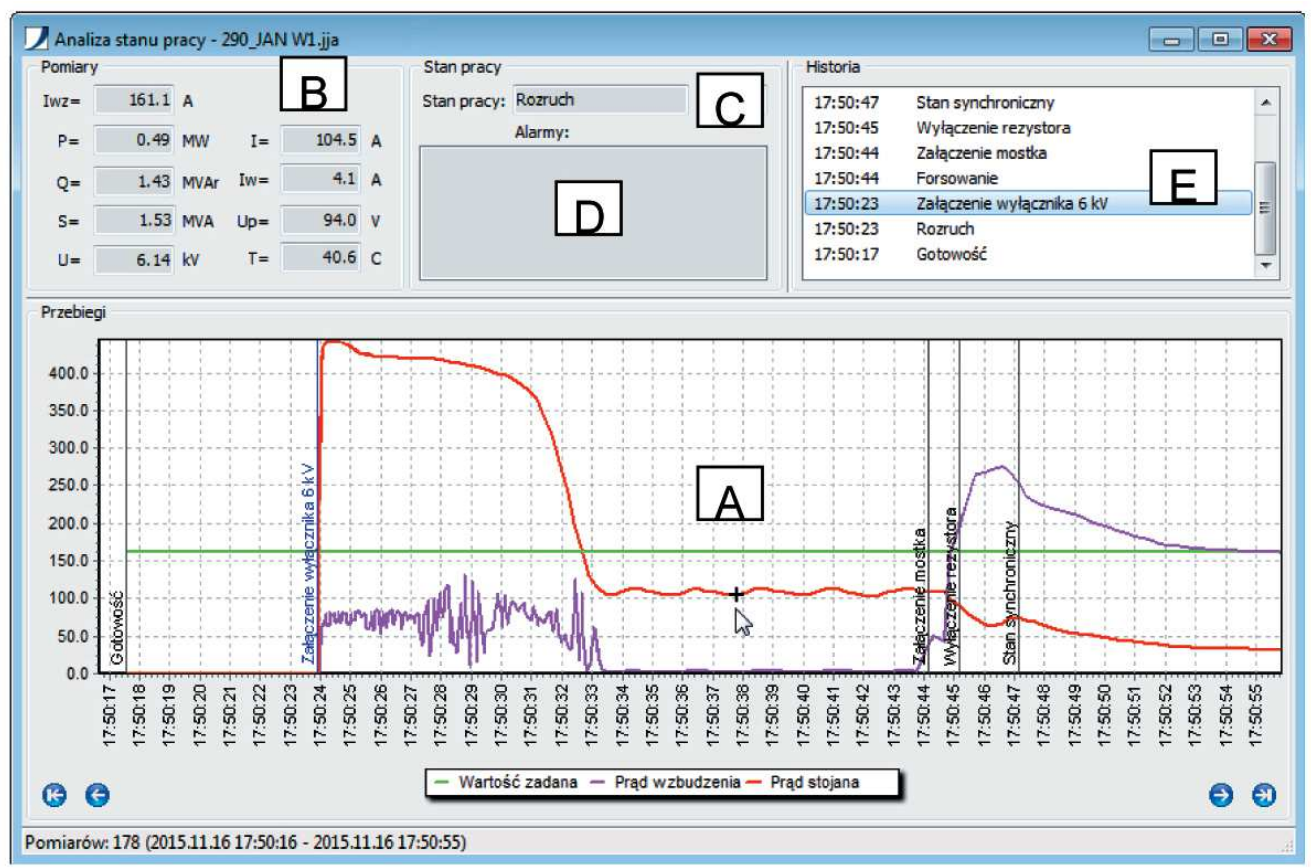

Fig. 9. Window for analysis of drive operating condition 
In the bottom part of the status analysis window (area A), the measurement waveforms from the selected time interval are displayed (with additional information from the event logging system). Placing the mouse cursor in any position of the graph displays the measured values for the indicated time in Area B, a description of the drive operating state in Area $\mathrm{C}$, and active alarms and failures in Area D. Area E of the window allows us to select an event from a list of registered events. Selecting an event from the list automatically scales and moves the graph in Area A to the appropriate time.

The analytical determination of the admissible operation range of the synchronic motor due to the admissible value of the load angle requires knowledge of synchronous reactances $X_{d}$ and $X_{q}$. Measurement of Mordey's curves enables the verification of the values accepted for calculation and possible correction of the limit associated with the minimum admissible field current.

Figure 10 shows a diagnostic software window that allows us to plot V-curves based on a series of measurements recorded in the synchronous state of the motor. The software allows us to select the active power range for each of the plotted curves and adjust the number of samples for plotting the values by the moving average.

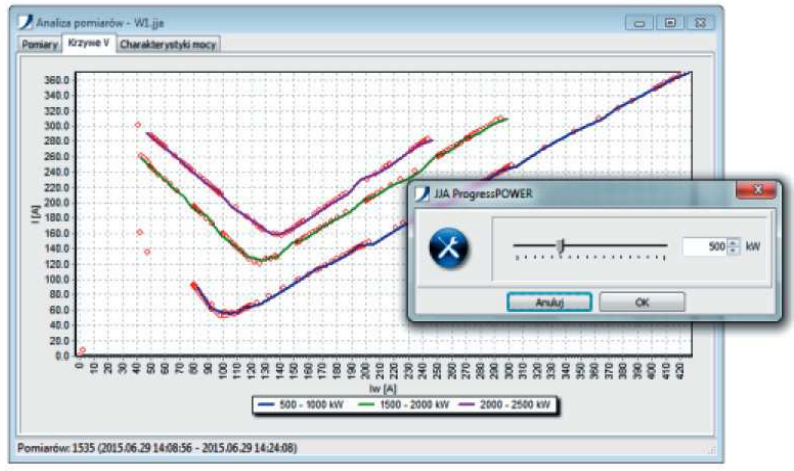

Fig. 10. Determination of Mordey's curves based on measurements of synchronous operation state

\section{SUMMARY}

The presented microprocessor-controlled excitation power supply unit for synchronous motors with diagnostic and service software developed in co-operation with the author is one of the most up-to-date examples on the market.
The use of this microprocessor-controlled device allows for the automation of the start-up of a synchronous motor, simplicity of operation, and reduction of drive failure. It also allows us to use the device in the automatic redundant systems in case of failure in the basic system.

Built-in communication interfaces allow for remotely controlling and monitoring the drive operation. The possibility of using a synchronous motor with the microprocessor-controller excitation system as an adjustable source of reactive power in a follow-up compensation system allows for the simple integration of the device with installed power quality assurance systems.

Diagnostic software with the ability to record drive operation parameters allows for an in-depth analysis of drive system behavior. Use of the presented software during the technological start-up of the device in the plant allows us to determine and diagnose the start-up parameters [5, 8-10] and the settings of the regulators and limitations parameters, ensuring the proper operation of the drive system.

The several-dozen implementations realized by the JJA Progress company (in co-operation with the author) into large-power synchronous motor drives, mainly mining ventilation fans systems, and the failure-free operation of the devices confirm the effectiveness of the solutions used and the usefulness of the developed diagnostic tools.

\section{References}

[1] Al-Hamrani M.M., Von Jouanne A., Wallace A.: Power factor correction in industrial facilities using adaptive excitation control of synchronous machines, Conference Record of the 2002 Annual Pulp and Paper Industry Technical Conference, Toronto, Ontario, Canada 2002: 148-154.

[2] Bajorek Z.: Teoria maszyn elektrycznych, Wydawnictwo Politechniki Rzeszowskiej, Rzeszów 1987.

[3] Campeanu A., Enache S., Vlad I., Liuba G., Augustinov L., Cautil I.: Simulation of asynchronous operation in high power salient pole synchronous machines, XXth International Conference on Electrical Machines (ICEM), Marseille 2012: 1823-1828.

[4] Colak I., Bayindir R., Bay O.F.: Reactive power compensation using a fuzzy logic controlled synchronous motor, "Energy Conversion and Management" 2003, 44: 2189-2204.

[5] Technical and engineering documentation of exciter Progress POWER. ENEL-PC, Gliwice 2011.

[6] Hyla M.: Automatic compensation of reactive power with a system for monitoring a $6 \mathrm{kV}$ electrical power grid in mine, "Mining - Informatics, Automation and Electrical Engineering" 2015, 2: 5-10.

[7] Hyla M.: Impact of voltage dips on the operations of a high- power synchronous motor with a reactive power controller, "Mining - Informatics, Automation and Electrical Engineering" 2016, 2: 5-13. 
[8] Hyla M.: Power supply unit for the excitation of a synchronous motor with a reactive power regulator, "Mining - Informatics, Automation and Electrical Engineering" 2015, 1: 17-21.

[9] Hyla M.: Rozruch silnika synchronicznego z mikroprocesorowym blokiem zasilania wzbudzenia, „Przegląd Elektrotechniczny" 2017, 4: 177-184.

[10] Hyla M.: Wybrane aspekty sterowania tyrystorowa wzbudnica silnika synchronicznego, V Ogólnopolska Konferencja Naukowa Modelowanie i Symulacja MIS-5, Kościelisko 2008, pp. 345-348.

[11] Igbinovia F.O., Fandi G., Švec J., Müller Z., Tlusty J.: Comparative review of reactive power compensation technologies, 16th International Scientific Conference on Electric Power Engineering (EPE), Kouty nad Desnou, 2015, pp. 2-7.

[12] Kaczmarek T., Zawirski K.: Układy napędowe z silnikiem synchronicznym, Wydawnictwo Politechniki Poznańskiej, Poznań 2000.

[13] Kay J.A., Paes R.H., Seggewiss J.G., Ellis R.G.: Methods for the control of large medium-voltage motors: application considerations and guidelines, IEEE Transactions on Industry Applications 2000, 36, 6: 1688-1696.

[14] Krishnamurthy B., Rexford J.: Web protocols and practice: HTTP/1.1, networking protocols, caching, and traffic measurement, Addison-Wesley Professional, Boston 2001.

[15] Latek W.: Teoria maszyn elektrycznych, WNT, Warszawa 1987.

[16] Mielczarek W.: USB. Uniwersalny interfejs szeregowy, Wydawnictwo Helion, Gliwice 2005.
[17] Modicon MODBUS Protocol Reference Guide, Modicon Inc., USA 1993.

[18] Plamitzer A.: Maszyny elektryczne, WNT, Warszawa 1986.

[19] Rozporządzenie Ministra Gospodarki z dnia 28 czerwca 2002 r. $w$ sprawie bezpieczeństwa i higieny pracy, prowadzenia ruchu oraz specjalistycznego zabezpieczenia przeciwpożarowego $w$ podziemnych zakładach górniczych (Dz.U. 2002, nr 139, poz. 1169; 2006, nr 124, poz. 863; 2010, nr 126, poz. 855).

[20] Siyan K.S., Parker T.: TCP/IP. Ksiegga eksperta, Wydawnictwo Helion, Gliwice 2002.

[21] Zalas P., Zawilak J.: Łagodzenie oraz skrócenie czasu procesu synchronizacji silników synchronicznych, "Elektrotechnika i Elektronika" 2006, 25, 2: 216-220.

[22] Zalas P., Zawilak J.: Wpływ układu sterowania prądem wzbudzenia na proces synchronizacji silnika synchronicznego, "Maszyny Elektryczne - Zeszyty Problemowe" 2006, 75: 83-88.

MARIAN HYLA, Ph.D., Eng. Faculty of Electrical Engineering Silesian University of Technology ul. B. Krzywoustego 2, 44-100 Gliwice, Poland marian.hyla@polsl.pl 